\title{
Stress- and age-related serum glucose changes in Spontaneously Hypertensive and Sprague-Dawley rats
}

\author{
JAMES J. STARZEC and DAVID F. BERGER \\ State University of New York College at Cortland, Cortland, New York
}

\begin{abstract}
The serum glucose levels of 90-day-old and 1-year-old male Spontaneously Hypertensive (SHR) and Sprague-Dawley (SD) rats were examined in two experiments. Half of each strain and age group were exposed to 51-min daily sessions of unpredictable, uncontrollable grid shocks during a 30-day period prior to sampling via decapitation. The other half remained undisturbed in their cages. Dietary intake was equated across all groups within each strain. Stress-induced increases were observed in both age groups, in both strains $(p s<.05)$. The SHRs showed an age $\times$ stress interaction with old, stressed animals having the highest levels $(p \mathrm{~s}<.05)$. Both younger SD groups had higher levels than corresponding older SD groups $(p s<.05)$.
\end{abstract}

Stress has been shown to increase serum glucose levels in rats (e.g., Balkin, 1981; Ehrentheil, Reyna, Adams, Giovanniello, \& Chen, 1967). The Spontaneously Hypertensive Rat (SHR) has been characterized by Kopin and his coworkers as hyperreactive physiologically to stressful stimulation, showing relatively higher levels of circulating catecholamines than age-matched Wistar Kyoto rats that are normotensive (see McCarty, Chiueh, \& Kopin, 1978; McCarty \& Kopin, 1978; and McCarty, Kvetnansky, Lake, Thoa, \& Kopin, 1978).

Although basal serum glucose levels tend to remain constant with age, Reaven and his associates (BrachoRomero \& Reaven, 1977; Nariyima et al., 1984; Reaven et al., 1983) and others have reported glucose intolerance and insulin resistance in older rats. Wexler (1981) reported that SHRs become progressively hyperglycemic and hyperlipidemic with increasing age. They also develop increased ACTH synthesis and secretion, increased adrenocortical responsiveness, and increased plasma corticosterone levels with aging.

The aim of the present study was to investigate the combined effects of stress and aging on the serum glucose response of SHRs. The SHRs were maintained on a highlipid diet as part of our work on the effects of psychological stress on cholesterol metabolism. Therefore, relatively higher glucose levels were expected because of the synergistic action of the diet and stress (Yamaguchi, Takashima, Masuyama, \& Matsuoka, 1978). It was expected that stress would result in elevated serum glucose, and that the old, stressed SHRs would have the highest levels. But first we examined the effects of all these con-

We thank Katherine Cranker, Joseph Miano, Patrick Graham, Jay Watsky, and Kathleen Clancy for their assistance during various phases of the study. Requests for reprints should be sent to J. Starzec, Psychology Department, State University College at Cortland, P.O. Box 2000, Cortland, NY 13045. ditions on the normotensive rats that we have studied most often, Sprague-Dawley (SD) rats.

\section{EXPERIMENT 1}

\section{Method}

Subjects. The subjects were 24 SD male rats obtained from Taconic Farms, Germantown, New York. Half were 90 days old (young), and the rest were 1 year old (old) at the beginning of the stress procedure. All were maintained on a diet consisting of $10 \%$ butter, $4 \%$ cholesterol, $1 \%$ cholic acid, and $85 \%$ powdered Purina Rodent Laboratory Chow.

Procedure. The animals within each age group were randomly assigned to either the stressed or nonstressed condition. This resulted in 6 animals in each cell of the design. Following 15 days of the diet alone, those in the stressed group were exposed to unpredictable, uncontrollable shocks for $51 \mathrm{~min}$ daily for $\mathbf{3 0}$ days. The shocks were delivered through the grids of six operant conditioning chambers with the levers removed. The $2-\mathrm{mA}$ shock pulses were $0.5 \mathrm{sec}$ in duration and were presented on a VI 60-sec schedule. The animals in the nonstressed condition stayed in their cages throughout the entire procedure. Our previous observations indicated that nonstressed rats eat more than stressed rats, and that 90 -day-old rats eat more than 1-year-old rats. Therefore, we used a yoking procedure to hold the amount of dietary intake constant. Both 90-day-old groups and the nonstressed 1-year-old group were fed the mean amount eaten by the old, stressed group on the previous day.

Following their 30th session, all stressed rats were immediately decapitated and their trunk blood was collected. The nonstressed rats were removed from their cages and sacrificed on the same days as the others. Sera were separated by centrifugation and samples from each animal were analyzed for glucose concentration, using a Beckman Glucose Analyzer 2.

\section{Results}

Food intake. The amounts of the diet eaten on the day the animals were sacrificed (see Table 1) were compared using a two-factor (stress condition $\times$ age) analysis of variance (ANOVA). The results showed no differences among the groups $(p>.05)$. The grand mean $( \pm$ SEM) was $21.2 \pm .68 \mathrm{~g}$.

Serum glucose. The animals' terminal serum glucose levels (see Table 1) were used to compute a similar two- 
factor ANOVA. There was a significant main effect of stress condition $[F(1,20)=48.7, p<.05]$. The means for the stressed and nonstressed conditions were 157.8 $\pm 5.52 \mathrm{mg} / \mathrm{dl}$ and $119.7 \pm 3.88 \mathrm{mg} / \mathrm{dl}$, respectively. The main effect of age was also significant $[F(1,20)=13.5$, $p<.05]$. The mean for the old animals was $128.7 \pm$ $7.00 \mathrm{mg} / \mathrm{dl}$. That for the young was $148.9 \pm 6.65 \mathrm{mg} / \mathrm{dl}$. There was no interaction.

\section{EXPERIMENT 2}

\section{Method}

The second experiment was a replication of the first in every way except for the subjects. They were 33 male SHRs of the same ages and from the same supplier as above. Each group had 8 animals except for the old, stressed group, which had 9.

\section{Results}

Food intake. The two-way unweighted means ANOVA of the amounts eaten on the last day (see Table 2) showed that our effort to equate food intake was again successful ( $p$ s $>.05$ ). The grand mean was $19.1 \pm .59 \mathrm{~g}$.

Serum glucose. The mean terminal serum glucose levels for each group are represented in Table 2. A similar ANOVA yielded a significant stress condition $\times$ age interaction $[F(1,29)=8.0, p<.05]$. Newman-Keuls comparisons for simple effects showed that both the old and young stressed groups differed from both nonstressed groups, and from each other, with, regard to their mean glucose levels ( $p s<.05$ ). The old and young nonstressed groups' mean values did not differ $(p>.05)$. The main effects of age $[F(1,29)=13.2]$ and stress condition $[F(1,29)=93.6]$ were also significant $(p s<.05)$.

\section{Discussion}

The results of both experiments showed that stress elevates serum glucose levels in old and young rats. The most extreme elevation occurred with the old SHRs, as expected. In that regard, the present results agree with those of Ehrentheil et al. (1967) and Wexler (1981). Presumably, exposure to the unpredictable, uncontrollable grid shocks results in sympathetic activation and release of catecholamines (McCarty \& Kopin, 1978), glucocorticoids (Berger, Starzec, \& Mason, 1981), inhibition of insulin release (Mason, 1968; Yamaguchi et al., 1978), and other changes which produce an elevation in serum glucose. These effects are exaggerated in the SHR (Wexler, 1981). Lower glucose tolerance

Table 1

Sprague-Dawley Rats

\begin{tabular}{|c|c|c|c|}
\hline \multirow[b]{2}{*}{ Age Group } & & \multicolumn{2}{|c|}{ Stress Condition } \\
\hline & & Stress & Nonstress \\
\hline \multicolumn{4}{|c|}{ Food Intake on Sampling Day (g) } \\
\hline 1-year-old & & $21.6 \pm 2.00$ & $21.4 \pm 2.36$ \\
\hline 90-day-old & & $21.0 \pm .03$ & $21.0 \pm .05$ \\
\hline \multicolumn{4}{|c|}{ Serum Glucose $(\mathrm{mg} / \mathrm{dl})$} \\
\hline 1-year-old & & $148.7 \pm 6.77$ & $108.7 \pm 3.12$ \\
\hline 90-day-old & & $166.8 \pm 7.44$ & $130.7 \pm 2.87$ \\
\hline \multicolumn{4}{|c|}{ Body Weight (g) } \\
\hline \multirow[t]{2}{*}{ 1-year-old } & Initial & $462.7 \pm 13.35$ & $471.8 \pm 14.91$ \\
\hline & Final & $472.8 \pm 18.94$ & $493.8 \pm 21.16$ \\
\hline \multirow[t]{2}{*}{ 90-day-old } & Initial & $361.5 \pm 4.19$ & $361.5 \pm 7.74$ \\
\hline & Final & $382.7 \pm 4.88$ & $391.8 \pm 6.15$ \\
\hline
\end{tabular}

Note-Values are means \pm SEMs.
Table 2

Spontaneously Hypertensive Rats

\begin{tabular}{lccc}
\hline & \multicolumn{3}{c}{ Stress Condition } \\
\cline { 2 - 4 } Age Group & Stress & Nonstress \\
\hline \multirow{5}{*}{ 1-year-old } & Food Intake on Sampling Day (g) \\
90-day-old & $20.0 \pm .69$ & $19.0 \pm .87$ \\
& $20.0 \pm .80$ & $17.4 \pm 1.95$ \\
1-year-old & Serum Glucose $(\mathrm{mg} / \mathrm{dl})$ \\
90-day-old & $242.0 \pm 14.13$ & $133.7 \pm 3.51$ \\
& \multicolumn{4}{c}{$186.0 \pm 6.46$} & $126.6 \pm 3.06$ \\
1-year-old & Initial & $379.4 \pm 9.44$ & $386.1 \pm 9.10$ \\
& Final & $367.6 \pm 11.27$ & $389.7 \pm 8.41$ \\
90-day-old & Initial & $265.1 \pm 5.06$ & $267.9 \pm 5.37$ \\
& Final & $289.3 \pm 4.29$ & $303.9 \pm 12.62$ \\
\hline
\end{tabular}

Note-Values are means \pm SEMs.

in older rats (e.g., Bracho-Romero \& Reaven, 1977), especially SHRs (Yamori et al., 1978), slowed the clearance of the glucose load from the blood so that by the time we sampled it several minutes later, the older SHRs still had the highest elevations.

In the present study, the younger SD rats had higher terminal serum glucose levels than their counterparts in the older groups. These results are not in agreement with those of Ehrentheil et al. (1967), who found higher stress-induced elevations in fasted 8-month-old than in 2-month-old C. D. Fisher rats. There are at least two possible explanations for the unexpected discrepancy. Unfortunately, the effects of circadian rhythms on circulating glucose were not controlled for (by balancing the representation from each group throughout the daily session times) in Experiment 1, as they were in Experiment 2, because the focus of the overall investigation was on cholesterol metabolism, which shows no time-ofday effects (Brown, Kovanen, \& Goldstein, 1979). Therefore, most of the young SDs were run between 5 and 11 p.m., whereas the old SDs were run before 3 p.m., as a matter of convenience. McMurtry and Wexler (1981) reported that plasma glucose is sufficiently higher in the evening to account for the differences we observed. Their light-dark cycle corresponded with ours.

In addition, our old SDs were approximately $168 \mathrm{~g}$ lighter than those of the same age studied by Narimiya et al. (1984) and others. The latter authors and Bracho-Romero and Reaven (1977) indicated that the glucose intolerance and insulin resistance seen in older (normotensive) rats is associated with the weight gain that accompanies aging.

\section{REFERENCES}

BALKIN, T. (1981). Effect of prior exposure to signalled versus unsignalled, uncontrollable shock on plasma glucose levels and the acquisition of a coping response. Unpublished master's thesis, State University of New York, Cortland, NY.

Berger, D. F., Starzec, J. J., \& Mason, E. B. (1981). The relationship between plasma corticosterone levels and leverpress avoidance vs. escape behaviors in rats. Physiological Psychology, 9, 81-86.

Bracho-Romero, E., \& ReAven, G. M. (1977). Effect of age and weight on plasma glucose and insulin responses in the rat. Journal of the American Geriatrics Society, 25, 299-302.

Brown, M. S., Kovanen, P. T., \& Goldstein, J. L. (1979). Receptormediated uptake of lipoprotein cholesterol and its utilization for steroid synthesis in the adrenal cortex. Recent Progress in Hormone Research, 35, 215-257.

Ehrentheil, O., Reyna, L., Adams, C., Giovanniello, T., \& Chen, E. (1967). Blood sugar response to electric shock stress in normal, adrenalectomized and hypophysectomized white rats. Diabetes, 16, 325-330.

MASON, J. W. (1968). Organization of the multiple endocrine responses to avoidance in the monkey. Psychosomatic Medicine, 30, 774-790.

McCarty, R., Chiueh, C. C., \& Kopin, I. J. (1978). Spontaneously hypertensive rats: Adrenergic hyperresponsivity to anticipation of electric shock. Behavioral Biology, 23, 180-188. 
MCCarTy, R., \& KopIn, I. J. (1978). Sympatho-adrenal medullary activity and behavior during exposure to footshock stress: A comparison of seven rat strains. Physiology \& Behavior, 21, 567-572.

McCarty, R., Kvetnansky, R., LAKE, C. R., ThOA, M. N., \& Kopin, I. J. (1978). Sympatho-adrenal responses of SHR and WKY rats to forced immobilization. Physiology \& Behavior, 21, 951-955.

McMurTry, J. P., \& WeXLer, B. C. (1981). Circadian rhythm of circulating glucose, insulin and growth hormone in spontaneously hypertensive rats. Life Sciences, 28, 2317-2322.

Narimiya, M., Azhar, S., Dolkas, C. B., Mondon, C. E., Sims, C., WRIGHT, D. W., \& REAVEN, G. M. (1984). Insulin resistance in older rats. American Journal of Physiology, 246 (Endocrine Metabolism 9), E397-E404.

Reaven, E., Wright, D., Mondon, C. E., Solomon, R., Ho, H., \& REAVEN, G. M. (1983). Effect of age and diet on insulin secretion and insulin action in the rat. Diabetes, 32, 175-180.
WeXLer, B. C. (1981). Histopathologic changes in aging male and female spontaneously hypertensive rats. Journal of Gerontology, 36, 514-519.

Yamaguchi, K., Takashima, S., Masuyama, T., \& Matsuoka, A. (1978). Effects of electric stress on insulin secretion and glucose metabolism in rats fed with a high fat diet. Endocrinology Japonica, $25,415-422$.

Yamori, Y., Ohtaka, M., Ueshima, H., Nara, Y., Horie, R., Shimamoto, T., \& КомасHI, Y. (1978). Glucose tolerance in spontaneously hypertensive rats. Japanese Circulation Journal, 42, 841-847.

(Manuscript received for publication December 19, 1985.) 